\title{
A Dimensão Afetiva no Ensino da Área Contábil: um experimento na aplicação da Autoeficácia
}

\author{
Maria Eugênia R. Araujo- UFRGS/UFMA euggenia2001@ gmail.com \\ Magda Bercht-PPGIE/UFRGS- bercht@inf.ufrgs.br \\ Ariel Behr-PPGA/UFRGS- ariel.behr@ufrgs.br
}

Resumo

\begin{abstract}
Este artigo relata um experimento de aplicação de curso configurado no construto da autoeficácia para apoiar a dimensão afetiva na formação do profissional em ciências contábeis. O objetivo do curso é estimular a autoeficácia no aluno e gerar mudança no seu comportamento. O conteúdo do curso versa sobre auditoria e foi desenvolvido na modalidade à distância na plataforma MOODLE. A aplicação modela a aprendizagem nos processos Atenção, Retenção, Produção e Motivação da experiência vicária por meio das atividades propostas com base nos métodos clínicos aplicados por Bandura nas fontes de restauração da autoeficácia. O curso foi aplicado com alunos de mestrado em ciências contábeis da UFRGS. A metodologia utilizada é de estudo de caso numa abordagem qualitativa e verifica em escala psicométrica de Autoeficácia Geral o percentil desse sentimento no aluno. Resultado: o construto pode ser adotado para apoiar o ensino e aprendizagem, nos processos modelados na aplicação da Autoeficácia.

Palavras chaves: Autoeficácia, Dimensão Afetiva, Experiência Vicária; Atividades, Ensino de Contabilidade

\section{The Affective Dimension in Accounting Education: An Experiment at Application of Self-Efficacy}

Abstract

This article describes about a course application experiment configured in the selfefficacy construct as support to the affective dimension in the training of professionals in accounting sciences. The objective is to show all the steps taken in creating the course to stimulate self-efficacy to the students as a generate changing in their behavior. The content of the course of the course is about auditing and it was developed by distance educational modality on the MOODLE platform. The application models learning in the Attention, Retention, Production and Motivation processes of vicarious experience through the proposed activities. The course was applied with 6 master's students in accounting sciences from UFRGS. The methodology used is case study in a qualitative approach.. Psychometric scale of General Self-efficacy was used to analyze student's performance. Result: the construct can be adopted as learning theory, in which the processes support modeled in the application of Self-efficacy

Keywords: Self-efficacy, Affective Dimension, Vicarious Experience; Tasks, Accounting Education 


\section{INTRODUÇÃO}

O presente artigo relata a experiência de elaborar e avaliar um curso à distância em contabilidade na subárea auditoria com metodologia que utiliza o construto da autoeficácia como apoio à abordagem afetiva no ensino.

No ensino, o afeto é pensado a partir das teorias de aprendizagem que estudam o comportamento humano nas vivências escolares ou acadêmicas, pois a afetividade integra o aprendizado humano e é inerente ao processo de formação dos alunos (SHUNK, et al 2008).

Ampliando essa visão, é importante que os docentes compreendam o significado de afetividade. Para Bercht (2001) a afetividade "pode ser conceituada como todo o domínio das emoções, dos sentimentos, das experiências sensíveis e, principalmente, da capacidade de entrar em contato com sensações, referindo-se às vivências dos indivíduos e às formas de expressão mais complexas e essencialmente humanas". A afetividade é entendida por esta autora como a dimensão afetiva, na pessoa vivenciada no ambiente do ensino acadêmico.

Em pesquisa realizada com professores da área contábil, ficou constatado que esses professores pouco conhecem, em suas práticas pedagógicas, teorias de aprendizagem a serem utilizadas no desenvolvimento do ensino que possam apoiar a afetividade durante o aprendizado tecnicista (VANDRUSCOLO e BERCHT, 2015). A composição curricular das disciplinas de projeto pedagógico dos cursos de graduação em ciências contábeis evidencia a ausência dessas práticas mesmo nas disciplinas que direcionam o ensino ao desenvolvimento de atributos e habilidades no aluno (CAMPOS e SIRLEY, 2012 \& KAVANAGH e LYNDAL, 2008)

Nesse contexto, a motivação para a produção deste artigo nasce na criação dos passos adotados na elaboração de um curso à distância em auditoria desenvolvido no ambiente MOODLE, Modular Object-Oriented Dynamic Learning Environment. A estrutura proposta no curso serve para experimentar ou testar o construto Autoeficácia de Bandura (1997) como teoria de aprendizagem que contribui na formação do profissional em contabilidade.

A escolha do construto da autoeficácia se deve à correspondência que esta autora faz na formação de competências atribuídas ao profissional Auditor-Contador que exige o sentimento de autoeficácia. Segundo Bandura (1989) as pessoas aceitam atividades e ambientes desafiadores quando acreditam em sua própria capacidade ou recursos para fazer, tendendo a evitar situações que não acreditam serem capazes de realizar. Estudos que investigaram a autoeficácia nos estudantes de ciências contábeis comprovam ser importante terem essa percepção para se sentirem capazes e confiantes em sua formação (NOYELLES, 2014; MIRANDA, et al 2014, CHEN \& CHOU, 2010).

Desse modo, justifica-se a importância de projetar um curso na área de Gestão e Auditoria com metodologia que busca aproximar os métodos aplicados por Bandura (1977) em clínica, originados nas fontes de autoeficácia, para adotar o construto da autoeficácia, motivador da afetividade no ensino em contabilidade.

Este artigo é estruturado em seções: seção 1 Introdução seção 2 O Construto da Autoeficácia; 3 Para que aplicar a autoeficácia no ensino da área contábil? 4 Elaboração do Curso; 5 Trabalhos Relacionados; 6 Metodologia; 7 Resultado e comentários na experiência; 8 Considerações Finais; Referências. 


\section{O CONSTRUTO DA AUTOEFICÁCIA}

Em Bandura (1997) e Hutz (2014) a autoeficácia é conceituada como a crença na capacidade de realizar uma determinada tarefa com base nos próprios recursos. Tais recursos são cognitivos, motivacionais e comportamentais, sendo a base da ação e motivação humana que orienta o comportamento residente na mente, capaz de conhecer e discernir (BANDURA, 1997;1993).

Contudo, o estudo da autoeficácia desenvolvido por Bandura (1997), em princípio, era destinado a tratar comportamento de medos e fobias, estados emocionais, mas evolui nos estudos de Schunk (et al 2008), Pajares e Olaz (1996), Zimmermann (2000) e Maddux (1999). Esses autores ampliaram a pesquisa para o estudo de comportamento com autoeficácia voltado para educação de crianças, adolescentes e universitários, nas mais diferentes áreas, o que tornou ainda mais difundida a compreensão dos métodos das fontes de autoeficácia.

A autoeficácia concentra a mudança de comportamento na pessoa, pela aprendizagem, e se desenvolve numa estrutura teórica relacionada a mecanismos ou ações psicológicos (BANDURA, 1997). Os efeitos desses mecanismos conduzem a uma mudança de comportamento pela geração de emoções e sentimentos elaborados na mente (DAMÁSIO, 2012), representando um sistema de afetos interpretado, neste estudo, como viés da afetividade no domínio do ensino em contabilidade.

Nesse sentido, é percebida a afetividade conceituada por Bercht (2001) em todos os processos de restauração das fontes de autoeficácia, experiência prévia, experiência vicária, persuasão verbal, excitação emocional, estudadas por Bandura (1997), que serviram de suporte para a projeção de uma metodologia de ensino para conteúdos em contabilidade que incita o afeto do aluno.

O próximo item aborda as fontes da autoeficácia para que se entenda como se dá o afeto na aprendizagem.

\subsection{Fontes da autoeficácia}

Bandura (1997) afirma que as fontes de informação de eficácia dão origem aos pensamentos de autoeficácia e servem para avaliar como esses pensamentos são elaborados e se estão refletidos nas experiências vivenciadas em diferentes circunstâncias. As fontes de autoeficácia são: experiência prévia; experiência vicária; persuasão verbal e feedback; estados fisiológicos e afetivos.

$\mathrm{Na}$ experiência prévia são consideradas as experiências que a pessoa já traz de situações passadas que lhes fazem sentir se é capaz ou não de realizar o que está sendo oferecido na situação que se apresenta. Para Bandura, as experiências positivas aumentam a força pessoal para realização, e experiências negativas podem levar a um sentimento de "incapacidade", dúvidas sobre si mesmo. Desse modo, a percepção da autoeficácia depende do modo como a pessoa lida com diferentes situações. Isto é, a lembrança afeta a pessoa na vivência presente. Por isso, Bandura (1997) considera aspectos pessoais como, estruturas prévias de autoconhecimento, significando que a pessoa, ao realizar tarefas, já possui um conhecimento de si e do ambiente que lhe cerca.

$\mathrm{Na}$ experiência vicária o autor considera que o comportamento não é desenvolvido exclusivamente de modo direto, mas também indireto, e que acontece por meio da observação e representação simbólica com outras pessoas e situações.

Para Bandura (1997), o efeito dos processos indiretos por observação pode ser 
tão grande e significativo como o efeito de aprendizagem direta. A aprendizagem por meio da observação indireta se refere a uma modelagem, representada por símbolos que podem resultar na aquisição de novas respostas. Por isso, o autor estabelece etapas ou mecanismos no processo de modelagem do aprendizado pela observação indireta que são: Atenção, Retenção, Reprodução e Motivação, (BANDURA,1997) como processos cognitivos que interagem no afetivo; para firmar a modelagem.

A Atenção ocorre de acordo com as características do modelo, que podem chamar atenção pela afetividade, complexidade e o valor funcional do comportamento, capacidade sensorial do observador, nível de interesse, motivação e reforços recebidos do passado.

A Retenção ocorre na representação do que foi observado. Bandura (1977) sustenta que uma vez "arquivada" a imagem ou descrição, pode ser revivida e reproduzida como nosso próprio comportamento. Nesse momento, imaginação e linguagem criam o modelo na forma de imagens mentais ou descrições verbais.

$\mathrm{Na}$ reprodução são traduzidas as imagens ou descrições no comportamento real. No ponto de reprodução, a capacidade para imitar melhora com a prática do comportamento. E as competências também melhoram pelo simples fato de imaginar fazendo o comportamento.

$\mathrm{Na}$ motivação, se relacionam três razões para a mesma: reforços externos, relacionados por efeitos incentivadores vindos do outro; reforços vicários, relacionados a padrões, como exemplo benefícios adquiridos; e reforços internos, relacionados pela autoavalição de processos motivacionais conforme o autor.

Na persuasão verbal é utilizada a sugestão para levar as pessoas a acreditarem no sucesso com suas dificuldades do passado, uma espécie de autossuperação. Entretanto, as expectativas de autoeficácia induzidas são mais fracas comparadas às próprias realizações da pessoa, uma vez que a base experimental não é a verdadeira.

Quanto à excitação emocional, a percepção de autoeficácia pode ser afetada nas situações em que as pessoas se sentem ameaçadas. Bandura (1997) acrescenta que o estresse é gerado por um estado de ansiedade (medo) e reduz o desempenho. Para o autor, as pessoas acreditam mais no seu sucesso quando não estão tensas ou agitadas. E adverte que o medo gera mais medo em situações estressantes, pelo fato de ocorrer uma antecipação de autoestimulação. O que eleva os níveis de ansiedade, que são maiores do que uma situação de ameaça, concluiu o autor.

\section{PARA QUE APLICAR A AUTOEFICÁCIA NO ENSINO DA ÁREA CONTÁBIL?}

Nas fontes de autoeficácia são encontrados métodos de restauração da autoeficácia e processos de aprendizagem. Portanto, a aplicação do construto da autoeficácia no ensino de conteúdos de contabilidade é recebida como medida necessária à convergência de um ensino tecnicista com comportamento humano, qualificando a competência técnica.

Zimmermann (2000) relata que o estudo da autoeficácia emerge como preditor eficaz de motivação na aprendizagem dos alunos. Para Bandura (1997), alunos que têm uma elevada autoeficácia, visualizam ambientes de sucesso que oferecem orientações positivas para apoiar suas ações e aqueles que duvidam de sua eficácia mais frequentemente apresentam estados de fracasso, enfatizando determinados aspectos do que pode dar errado.

Segundo Noyelles et al, (2014) as características afetivas no profissional de contabilidade são importantes para sua atuação no mercado globalizado, e podem ser trabalhadas a partir da motivação de comportamento autoconfiante, para enfrentamento 
de desafios profissionais. Desse modo, professores devem buscar pelo conhecimento de teorias de aprendizagem para que possam desenvolver com seus alunos práticas didático-pedagógicas que integrem afetividade e cognição em sua formação (SCHUNK,et al 2008; ZIMMERMAN, 2000).

Desse modo, busca-se apresentar um caminho na elaboração de um curso adotando os métodos estudados por Bandura na autoeficácia para tornar o ensino mais afetivo.

\section{ELABORAÇÃO DO CURSO}

\subsection{Eixo teórico da Autoeficácia no curso}

Esta seção trata da experiência de elaboração de um curso à distância no MOODLE, com 15 horas, equivalente a um (1) crédito na disciplina Auditoria como parte de uma pesquisa de tese que investiga a aprendizagem com autoeficácia na formação do profissional em contabilidade.

O enfoque do curso consiste em ensinar sobre os riscos que afetam uma empresa a ser auditada e como a gestão de empresa identifica e lida com essas ameaças.

O curso teve como característica evidenciar em sua configuração o aprendizado observacional indireto. Nesse modo, a ênfase maior dada ao curso foi o método adotado na fonte de autoeficácia, experiência vicária, que é uma experiência viva, e trabalha os processos de aprendizagem: Atenção, Retenção, Reprodução e Motivação (BANDURA, 1997).

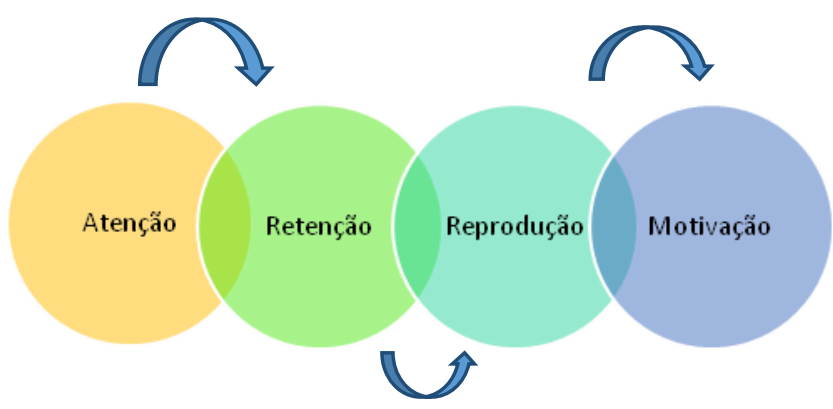

Figura 1 Processos de Aprendizagem observacional indiretos na experiência vicária, criado pela autora.

Em seguida foi realizada a interpretação conceitual de cada categoria que compõe o aprendizado na experiência vicária.

Atenção é fase inicial do aprendizado vicário indireto, que acontece no primeiro contato com o conteúdo ou informação. Nessa fase, atributos do observador (aluno) são ativados, como por exemplo a percepção sobre a informação vista ou ouvida, que leva à seleção da informação para sua elaboração. Foram utilizadas imagens para ilustrar a ideia de cada conteúdo do curso. No material pedagógico foram usadas cores vivas no fundo dos textos, e os conteúdos organizados de modo encadeado para conceitos e ideias, cabendo ao aluno promover seu processo de observação a partir de seus próprios atributos, como percepções, cognição, restrições e preferências (BANDURA, 1997, p. 89).

A Retenção é a fase em que é elaborada a cognição e o ensaio na mente. $\mathrm{Na}$ elaboração da cognição ocorre a identificação simbólica do conteúdo ou informação, e a organização cognitiva desse conteúdo ou informação. No ensaio é feito o treino cognitivo ou raciocínio e o movimento na compreensão do conteúdo e informação. Para 
facilitar esse processo, foi adotado o uso de vídeo e áudio vinculado à estrutura de conteúdo aos slides. Desse modo, a atenção visual e auditiva, no material pedagógico facilita a retenção do conteúdo ou informação. Nessa etapa ocorre a junção articulada de estruturas e habilidades cognitivas no aluno.

$\mathrm{Na}$ fase de produção, a retenção de conteúdo ou informação promove na mente do aluno uma orientação de como representar. Ao mesmo tempo em que o aluno em sua mente, faz ajustes sobre o que reteve, significando que de posse do conteúdo ou informação o aluno consegue dar uma resposta. Nesse aprendizado, o aluno ao mesmo tempo relaciona palavras, ideias ao que reteve. Nessa etapa são acionadas a capacidade física e habilidades do aluno. E no curso foi utilizado como reforço a esse momento de produção do aprendizado, slide com áudio para explicação do conteúdo e de como o aluno deve responder a atividade. Relembrando ao aluno a explicação.

A última fase do aprendizado vicário ocorre no reforço do processo de motivação. Para Bandura (1997) a motivação pode ser externa, vicária e autoincentivos. Os atributos do observador ou aluno são: incentivo, comparação social e normas internas.

Para motivação externa foi considerado o ambiente MOODLE, com recursos de fórum, enquete, à disposição do material de conteúdo e atividades na página do curso. Além de vídeo motivacional, a utilização de frases motivacionais no início de cada conteúdo. Como autoincentivo, as atividades foram elaboradas de modo a fazer com que o aluno interaja com atividades práticas atuais, que refletem a realidade de empresas e o mercado. Desse modo, motiva o aluno à aprendizagem de saber posicionar-se frente às situações similares. Nesse sentido, a motivação no aluno está em saber fazer a comparação do aprendizado com a realidade, além de ajudá-lo a buscar seus padrões internos e dar preferência às suas escolhas de como deseja ou não atuar.

\subsection{O Modelo Pedagógico do Curso}

$\mathrm{Na}$ elaboração do curso, o modelo pedagógico de ensino compreendido pela arquitetura e design pedagógico (BEHAR, 2009) foram apoiados no eixo teórico da teoria da autoeficácia. $\mathrm{Na}$ arquitetura pedagógica, foram descritos os elementos: planejamento, conteúdo, atividades e ambiente virtual de ensino e aprendizagem. No design foi projetada a disposição na plataforma, sequência das informações evidenciadas, vídeos, imagens e modo de apresentação dos Conteúdos e Atividades, ilustrado na figura 2.

O MOODLE, como suporte tecnológico, permitiu elaborar o curso de modo assíncrono, respeitando o ritmo, mais rápido ou devagar, do aluno de ciências contábeis. Os recursos disponíveis aos usuários do MOODLE favoreceram a imersão no aprendizado na fonte de autoeficácia, experiência vicária, facilitando a estratégia de inserção de vídeo e áudio, que na experiência vicária são utilizados como modelo de aprendizagem por observação. As ferramentas do MOODLE utilizadas para o curso foram: atividades, rótulo para inserção de informação no formato de texto na página do curso, para inserção de figuras, ferramenta de inserção de arquivos em powerpoint e moviemaker, textos, vídeos e áudios e recursos, fórum para perguntas e mensagens, atividade com enquete e questionário. 


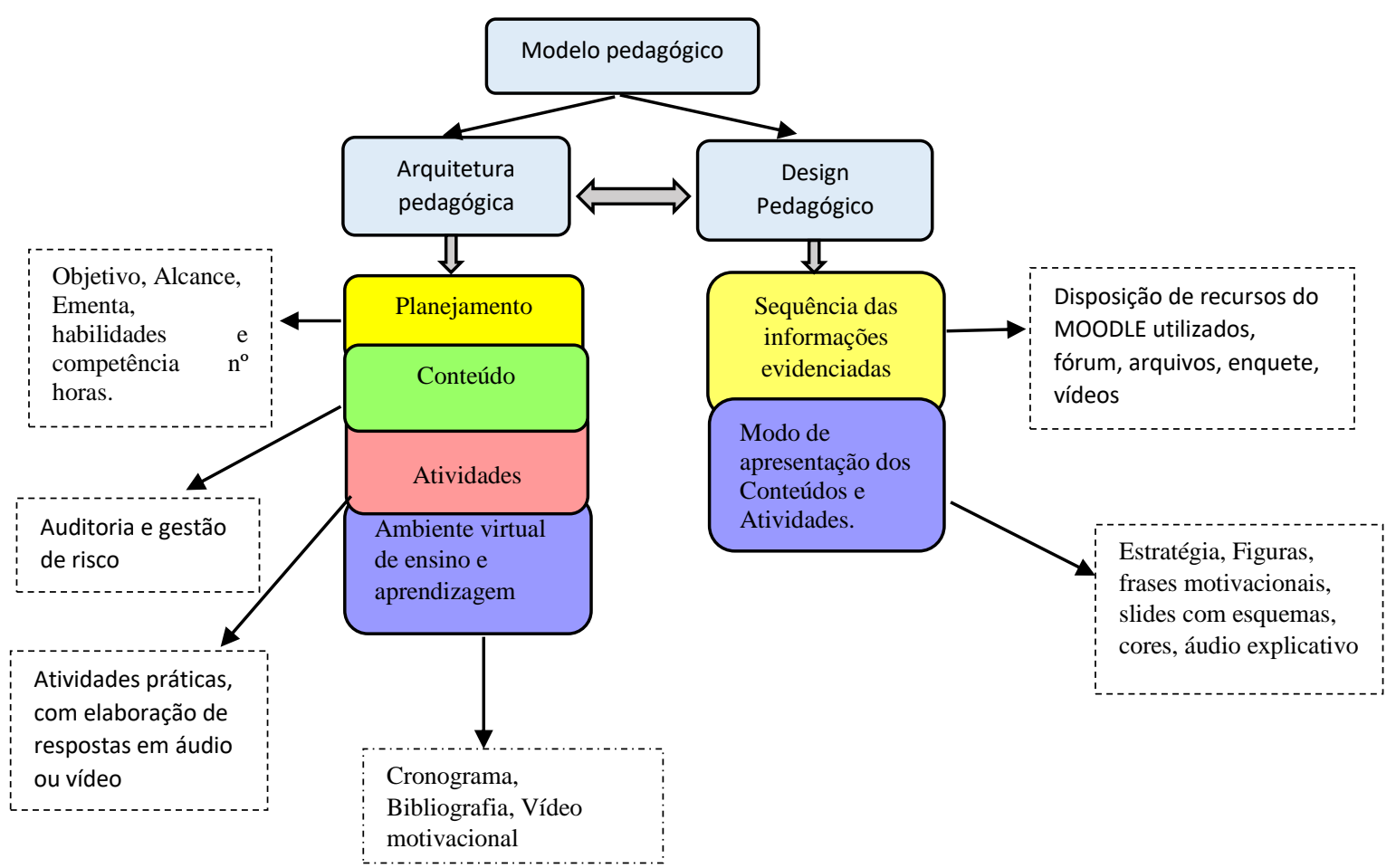

Figura 2 Modelo Pedagógico do curso de Gestão de Risco e Planejamento em Auditoria. Adaptado de Behar (2007).

Para avaliar o aluno no curso foram adotados os critérios de análise, o conteúdo da resposta dada pelos alunos e a expressão no conteúdo. Para tanto, foram observados os processos da experiência vicária: Atenção, Retenção, Produção e Motivação. Atenção, foram observadas as mensagens dos alunos quanto às dúvidas ou questionamentos, assim como o relatório de logs, mostrando a quantidade de acessos por dia e hora à plataforma. Retenção, foi avaliada à qualidade das respostas dadas se correspondem ao conteúdo. Produção, o modo como o aluno responde e expressa o conteúdo se é com característica de apropriação ou reprodução literal do material que contém o conteúdo. E Motivação, pela tempestividade em responder as atividades e interações do aluno no ambiente MOODLE. Como feedback da avaliação do curso pelos alunos e confirmação desses processos foram propostas seis questões para serem respondidas. As questões abordaram aspectos físicos dos materiais, qualidade do conteúdo e estratégias adotadas no curso, assim como pontos fracos do curso, pedido como sugestões, para aprimoramento do curso quando de sua implementação. Essas questões foram inseridas no modelo de questionário aberto do MOODLE, no final da página do curso.

\section{TRABALHOS RELACIONADOS}

No levantamento de pesquisas que aplicaram a autoeficácia no ensino de contabilidade, fica demonstrado que este construto tem sido estudado em ampla perspectiva, como a aplicação descrita nos artigos "Exploring the Dimensions of SelfEfficacy in Virtual World Learning: Environment, Task, and Content" (NOYELLES, et al, 2014) e de Cheng and Chiou (2010) "Achievement, Attributions, Self-Efficacy, and Goal setting by Accounting Undergraduates". A pesquisa de Noyelles (et al, 2014) explora a dimensão da autoeficácia de estudantes universitários relacionando atividades acadêmicas no mundo virtual aberto Second Life (SL) e concluiu que existem diferenças nas dimensões de autoeficácia em domínios específicos estudados, como: 
Autoeficácia no Ambiente do Mundo Virtual (MV), Autoeficácia no Domínio de Aprendizagem e Autoeficácia do Domínio Virtual de Aprendizagem Mundial (DVAM). Constatou, ainda, que a Autoeficácia no Ambiente do (MV) e a Autoeficácia do (DVAM) são correlacionadas ao fluxo de aprendizagem. A pesquisa de Noyelles (et al, 2014) se preocupou com a autoeficácia do aluno em três domínios diferenciados, considerando a interação do aluno em cada domínio, prevalecendo as características nos domínios investigados.

Para esta pesquisa a autora adota no MOODLE o processo da experiência vicária, na perspectiva de os alunos vivenciarem na sua dimensão afetiva a autoeficácia por meio de recurso de áudio e/ou vídeo.

A pesquisa Determinantes do Desempenho Acadêmico em Ciências Contábeis: Uma Análise de Variáveis Comportamentais (Miranda, et al, 2014) investigou por método estatístico a correlação na associação entre variáveis comportamentais e desempenho acadêmico de alunos do curso de ciências contábeis de uma universidade pública brasileira, incluindo a autoeficácia como variável analisada, não encontrando associação entre autoeficácia e o desempenho dos alunos. Nessa pesquisa, os autores investigaram a autoeficácia como variável de interferência no desempenho dos alunos e o resultado foi de que a autoeficácia não interfere no desempenho do aluno, diferente da proposta deste artigo que busca na autoeficácia um componente afetivo que pode ser trabalhado no contexto acadêmico.

E a pesquisa de Cheng e Chiou (2010) teve como objetivo examinar as correlações entre duas medidas de autoeficácia contábil, a realização de metas realizadas e os escores obtidos pelos alunos no teste de práticas contábeis (proficiência). $\mathrm{O}$ estudo conclui que os alunos com maior autoeficácia percebida tiveram melhor desempenho nos testes de proficiência e definem metas mais elevadas para outros testes realizados, obtendo melhores resultados. O estabelecimento de metas mediu a relação de autoeficácia inicial com o desempenho subsequente do teste. $\mathrm{O}$ experimento feito nesse trabalho resultou da análise na aplicação de um questionário geral de autoeficácia, sem considerar resultados individuais dos alunos. Este trabalho difere desta pesquisa por ser um estudo individualizado pois se preocupa com a afetividade em cada aluno.

\section{METODOLOGIA}

A pesquisa é de natureza qualitativa com características descritivas, (SAMPIERI et al, 2013) pois, apresenta a inserção do modelo da experiência vicária-como caminho para promover o aprendizado com autoeficácia na estruturação de cursos. Utiliza o método estudo de caso na análise (YIN,2015), e define como unidades de análise para aplicação da pesquisa: a autoeficácia do aluno, o afeto representado no desempenho e o ambiente MOODLE. As categorias consideradas na análise dessas unidades foram o percentil da autoeficácia do aluno e sexo.

A coleta de dados definidos na pesquisa foi o questionário de Autoeficácia Geral, na escala likert disponível no google docs com link para o MOODLE, e observações dos alunos no ambiente. Esses critérios e procedimentos foram adotados para comprovar as premissas norteadoras na elaboração do experimento que são: a Autoeficácia pode ser motivada por docentes a partir da arquitetura e design de um curso. A Mediação com tecnologia ajuda o docente a motivar o afeto no ensino. 


\subsection{Ambiente e Características do curso}

O curso Gestão de Risco e Planejamento em Auditoria foi desenvolvido no laboratório de informática do Centro Interdisciplinar de Novas Tecnologias em Educação do CINTED/UFRGS, em que está situado o Programa de Doutorado em Informática na Educação PPGIE. Foi criado para testar o reforço da auteoficácia afetiva no ensino. Entretanto, a natureza da pesquisa requer que o mesmo seja feito com duas turmas, por isso foi replicado na plataforma com duas perspectivas - com e sem estratégias de autoeficácia afetiva da experiência vicária. Essa conduta foi adotada para que fosse possível comparar o resultado em cada turma. Os cursos são semelhantes em conteúdo diferindo apenas na estratégia de elaboração das atividades. As turmas criadas para os cursos foram denominadas Gestão de Risco e Planejamento em Auditoria Turma 1(como reforço da auteoficácia afetiva) e Gestão de Risco e Planejamento em Auditoria - Turma 2 (sem o reforço da autoeficácia afetiva). O curso teve sua realização de um mês, de 01 a 31 de outubro de 2016, período que foi definido considerando a disponibilidade dos alunos

\subsection{Participantes}

Foram convidados seis alunos de Mestrado em Ciências Contábeis da Universidade Federal do Rio Grande do Sul por meio de contato via e-mail, sendo enviado Termo de Consentimento Livre e Esclarecido para saber se tinham interesse em participar da pesquisa, e informando o procedimento ético adotado na pesquisa. Dos seis alunos, 5 mulheres e 1 homem, todos se inscreveram no curso, mas quatro mulheres e o homem desistiram. Foi adotado o procedimento de consulta por e-mail para saber o motivo de desistência, uma das mulheres não se manifestou, e o homem e três mulheres se manifestaram alegando que em função do período do curso não dispunham de tempo.

Uma aluna iniciou e concluiu o curso de teste, com reforço da autoeficácia afetiva. Após resposta de aceite, houve o cadastramento da aluna na plataforma MOODLE, sendo informado login e senha de acesso ao curso e dada orientação de como proceder na plataforma para realização do curso.

Considerando este curso, a primeira versão, se justifica a sua realização com uma participante na pesquisa. Nesta versão foram observados a estrutura e funcionamento do curso, dimensionamento das atividades para 15 horas, o uso da plataforma MOODLE com os seus recursos, dificuldades percebidas pela aluna durante o curso e avaliação de juízes, que foram: docentes em contabilidade, educação, psicologia e profissional de psicologia que atua em consultoria de empresa.

\subsection{Procedimentos adotados no curso.}

\subsubsection{Procedimentos adotados na plataforma MOODLE.}

No ambiente MOODLE, foram adotados cuidados para que não houvesse dúvidas para o aluno e não impedisse a realização do curso por outros alunos. Logo, respeitando a coleta de dados do questionário, foi aberta uma sala para o Questionário de Autoeficácia Geral 1, que representou o primeiro dado coletado. Esse procedimento foi adotado para que alunos que se inscrevessem posteriormente não pulassem etapas, caso o questionário estivesse na mesma página do curso. $\mathrm{O}$ aluno responde ao questionário 
com link no googledocs e a resposta é remetida para o e-mail desta pesquisadora em uma planilha do Excel. De posse desses dados é feita a análise do percentil, esclarecemos que neste experimento foi adotada a tabela de normas específica para mulheres para análise do resultado (HUTZ, 2014, p.117).

Após resposta ao questionário, o aluno é alocado em uma das salas do curso. Como apenas uma aluna manifestou interesse foi alocada na turma do curso com reforço da autoeficácia afetiva, Turma -1, para que fossem experimentadas as estratégias propostas para aplicação da teoria da autoeficácia no ensino de contabilidade.

Na página do curso, o conteúdo foi dividido em três partes. E segue a disposição: frase motivacional, imagem, conteúdo, exemplo, vídeo explicativo da atividade, atividade do aluno.

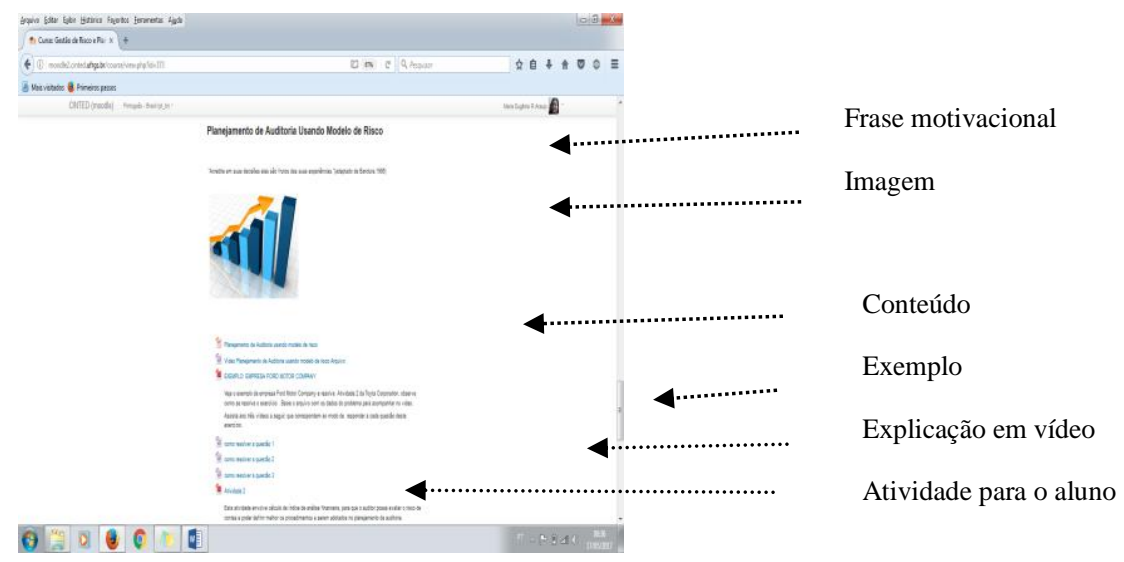

Figura 3 Disposição de conteúdo no MOODLE

\subsubsection{Avaliação de Juízes especialistas}

Para validar as estratégias propostas no curso com reforço da autoeficácia, foi apresentado a quatro juízes especialistas, conforme quadro abaixo. Ressaltando que as recomendações foram acatadas, sendo implementadas no curso com nova versão para turmas futuras.

\begin{tabular}{|l|l|l|l|}
\hline $\begin{array}{l}\text { Profissional juiz especialista e } \\
\text { Tempo de atuação na área }\end{array}$ & Formação & Titularidade & Recomendação na avaliação \\
\hline $\begin{array}{l}\text { Professor da UFRGS Departamento de } \\
\text { Educação mais de 30 anos de atuação. }\end{array}$ & Pedagogia & Livre Docente & $\begin{array}{l}\text { Configurar o curso na plataforma de modo a } \\
\text { evidenciar a teoria de Bandura, sugestão } \\
\text { colocar frases motivacionais com ideias do } \\
\text { autor. }\end{array}$ \\
\hline $\begin{array}{l}\text { Professor UFRGS Departamento, de } \\
\text { Psicologia pesquisador mais de 25 anos. }\end{array}$ & Psicologia & Doutor & $\begin{array}{l}\text { Quando da implementação do curso, inserir } \\
\text { a escala de autoestima para relacionar a } \\
\text { autoeficácia. }\end{array}$ \\
\hline $\begin{array}{l}\text { Consultora empresarial, atuação mais de 7 } \\
\text { anos. Consultório Particular }\end{array}$ & Psicologia & Doutor & $\begin{array}{l}\text { Que fosse inserido um vídeo como modelo } \\
\text { de aprendizado para o aluno, ensinando a } \\
\text { responder a atividade final. }\end{array}$ \\
\hline $\begin{array}{l}\text { Professor UFMA Departamento de Ciências } \\
\text { Contábeis e Administração, Auditor no Estado } \\
\text { do Maranhão. Atuação mais de 20 anos. }\end{array}$ & $\begin{array}{l}\text { Ciências } \\
\text { Contábeis }\end{array}$ & $\begin{array}{l}\text { Mestre } \\
\text { Ciências } \\
\text { Contábeis }\end{array}$ & $\begin{array}{l}\text { Que mantivesse o conteúdo das atividades } \\
\text { do modo como estava sendo pedido. }\end{array}$ \\
\hline
\end{tabular}

Quadro 1- Avaliação de Juízes na pesquisa, criado pela autora. 


\subsubsection{Procedimento de Avalição no curso}

Nesta etapa da pesquisa foi necessário fazer alteração na metodologia referente ao método comparativo experimental adotado, para o estudo de caso com análise de caso único. Por isso foram seguidos com mais detalhes, os critérios da teoria de Bandura Atenção, Retenção, Produção e Motivação. O foco da análise volta-se para o conteúdo e expressão desse conteúdo pela aluna.

\section{RESULTADO E COMENTÁRIO NA EXPERIÊNCIA}

Como resultado da aplicação do curso é importante destacar que os processos Atenção, Retenção, Produção e Motivação, acontecem no momento do ensino. Esses processos foram evidenciados no experimento pelas interações, da aluna $\mathbf{A}$ realizadas no ambiente MOODLE.

Para o processo de Atenção foi observado o número de acessos feitos na plataforma em cada unidade de conteúdo. O acesso ao material de estudo tem confirmação no relatório de logs gerado no Moodle em formato Excel. Nesse relatório é evidenciado, data, hora, nome, evento, usuário afetado, contexto, componente, nome do evento, descrição, origem e endereço de IP. A Retenção e Produção do conteúdo foram observadas nas respostas às atividades, quanto à qualidade da mesma em atender ou não a solução da atividade e o modo como foi expressada ou desenvolvida. $\mathrm{Na}$ atividade 1 a aluna $\mathbf{A}$ optou pelo recurso de áudio, e respondeu de modo correto, verificada a Retenção, do conteúdo. A Produção percebida na ação de resposta no áudio. A aluna demonstrou ter conseguido apropriar-se do conteúdo. A atividade 2 não foi realizada e está autora/professora/tutora, fez intervenção na plataforma. A aluna justificou que a atividade era complexa. A não realização da atividade impediu a aplicação do conceito de autoeficácia que busca dotar o aluno de encorajamento e enfrentamento (BANDURA,1997).

$\mathrm{Na}$ atividade 3, a aluna não utilizou nem áudio e nem vídeo em sua resposta. Enviou arquivo de texto com a resposta certa. A Motivação para as tarefas 2 e 3 é observada segundo o entendimento dos padrões internos do processo de motivação (BANDURA,1997) que na aluna, para a atividade 2 e 3 comprometeram o seu desempenho nessa atividade. Contudo em feedback via e-mail a aluna afirmou ter sido positiva a elaboração de ações pedagógicas no modo das estratégias áudio ou vídeo utilizadas nas atividades. E afirmou que "o curso tem qualidade no conteúdo por estar atualizado e compatível com o mercado". Por fim, declarou ter sido positiva a experiência e que aprendeu um modo diferente de responder atividade e avaliar o aluno quando atuar como docente junto aos mesmos.

A partir do resultado percebido e obedecendo o aspecto qualitativo do estudo de caso foi adotada a análise com estratégia de descrição do caso e a triangulação com diferentes fontes de evidência (YIN,2015). Desse modo foram analisadas as interações da autoeficácia com os fatores sexo e desempenho.

$\mathrm{Na}$ interação autoeficácia e sexo, o resultado do percentil de autoeficácia da aluna A identificado no questionário de autoeficácia geral 1 e autoeficácia geral 2, está maior que a média da autoeficácia para mulheres. A diferença no percentil do primeiro questionário para o segundo questionário foi de 15. A literatura sobre autoeficácia aponta diferença na média e desvio padrão entre homem e mulher (HUTZ,2014). Para Bandura (1997), essa diferença é resultado de conceitos prévios originados em 
estereótipos culturais e supergeneralização preditiva como fator de autoavaliação comparativa entre mulheres e homens.

$\mathrm{Na}$ interação autoeficácia e desempenho a aluna $\mathbf{A}$ apresentou um bom desempenho, originado nos processos de Atenção, Retenção, Produção e Motivação, admitido pela tomada de consciência da aluna e sua percepção de aprendizagem no curso.

\begin{tabular}{|l|c|c|}
\hline \multicolumn{1}{|c|}{$\begin{array}{c}\text { Aluno A (sexo feminino) } \\
\text { Idade 25 a 30 anos }\end{array}$} & PERCENTIL & Desempenho \\
\cline { 1 - 2 } $\begin{array}{l}\text { Questionário Autoeficácia } \\
\text { Geral 1 }\end{array}$ & 70 & 9,00 \\
\cline { 1 - 2 } $\begin{array}{l}\text { Questionário Autoeficácia } \\
\text { Geral 2 }\end{array}$ & 85 & \\
\hline
\end{tabular}

Quadro 1 -Resultado da aplicação do construto de autoeficácia no curso

\section{CONSIDERAÇÕES FINAIS}

Nesta pesquisa, observou-se que o construto da autoeficácia pode ser adotado como qualidade pedagógica das teorias de aprendizagem.

A revisão de literatura dá subsídios para compreensão de sua aplicação, pois a prática do curso confirmou aspectos teóricos estudados por Bandura (1997) e observações registradas na literatura Schunk (et al, 2008); Zimermann (2000).

A dimensão afetiva da aluna foi expressada no seu comportamento no curso e pela mudança de comportamento confirmada em sua declaração de ter aprendido um modo diferente de atuar como docente com seus alunos.

$\mathrm{O}$ estudo mostrou que o aluno sinaliza quando lhe é exigido esforço, o que leva a crer ser este ponto favorável à aplicação dos métodos das fontes de autoeficácia. Considera-se ser este ponto fundamental a ser dada atenção pelo professor em relação a seus alunos e ao que está sendo cobrado.

Os ajustes propostos foram feitos para aplicação do curso com novas turmas.

E como contribuição do estudo, a utilização de estratégias que utilizem ferramentas tecnológicas disponíveis aos alunos, como por exemplo uso de computadores e o celular, que permitem arquivo de áudio e vídeo que seja adotada como modelagem de aprendizagem para dar suporte ao ensino trabalhando o afeto no aluno através do conteúdo e expressão do conhecimento.

\section{REFERÊNCIA}

BANDURA, Albert. Self-efficacy: the exercise of control. USA W.H.Freeman and Company. 1997.

Perceived self-efficacy in cognitive development and functioning. Educational Psychologist, 28, 117-148, 1993.

. Human Agency in Social Cognitive Theory. American Psychologist, 44(9),1989, p.1175-1184

BANDURA, Albert. et al. Multifaceted impact of self-efficacy beliefs on academic functioning. v. 67, n. 3, p. 1206-1222, jun., 1996. Disponível em: <www.uky.edu/ eushe2/Bandura/Bandura1996CD.pdf>. Acesso em: 24 jun. 2013. 
BERCHT, MAGDA. Em direção a agentes pedagógicos com dimensões afetivas. Porto Alegre. UFRGS.2001.Tese.

BEHAR, Patricia A. Modelos pedagógicos em ensino a distância.Porto Alegre.Artmed. 2009.

BONG, Mimi. Generality of academic self-eficacy judgments:evidence hierachical relations. Journal of educational psycology.1997.v.89.n.4.p696-709

CHENG, Py-Yueh; CHIOU, Wen-Bin. Achievement, attribuitions self-efficacy and goal setting by accouting. PLUBMED Feb;2010. Psychol Rep.disponível em <https://www.ncbi.nlm.nih.gov/pubmed/20402427> Acesso em: 14.03.2015

DAMÁSIO, Antonio. O erro de Descartes. Companhia das Letras. 2012.

HUTZ, C. S. Avaliação em psicologia positiva. Porto Alegre: Artmed, 2014.

KAVANAGH, M. H.; DRENNAN, L. What skills and attributes does an accounting graduate need? Evidence from student perceptions and employer expectations. Accounting and Finance v. 48. 2. ed. p. 279-300. jun. 2008.

MADDUX, J. E.; Self-efficacy: (in press). SNYDER, C. R.; LOPEZ, S. J. (Eds). George Mason. Handbook of positive psychology. The Power of Believing you can. University New York: Oxford University Press. (2004).

MIRANDA, G J.; MAMEDE, S de P N; MARQUES, A V C e ROGERS Pablo: Determinantes do desempenho acadêmico em ciências contábeis: uma análise de variáveis comportamentais. Revista: Novas perspectivas na pesquisa contábil.XIV Congresso USP.Controladoria e Contabilidade.São Paulo 21 a 23 de julho de 2014.

NOYELLE ,A. HORNK,S;JONHSON.R. Exploring the imersives of self-efficacy in virtual world learning: envoirement, task and content. Merlot Journal of online learning and teaching. Vol.10.n ${ }^{\circ}$, june 2014.

Pajares, F. e Olaz, F. (2008). Teoria social cognitiva e autoeficácia: uma visão geral. Em: Bandura, A.; Azzi, R.G. e Polydoro, S. Teoria Social Cognitiva - Conceitos Básicos. (pp. 97- 114). São Paulo: Artmed.

SCHUNK, D. H.; PINTRICH, P. R.; MEECE, J. L. Motivation in education: teory, research and applications. 3. ed. Pearson Merrill Prentice Hall, 2008.

VENDRUSCOLO, M. I.; BERCHT, M. Prática pedagógica de docentes de ciências contábeis da região sul e sudeste do brasil: um estudo da percepção da afetividade. ConTexto, Porto Alegre, v. 15, n. 29, p. 113-128, jan./abr. 2015. Disponível em: < http://seer.ufrgs.br/index.php/ConTexto/article/view/53406> Acesso em: 20.05.2015

ZIMMERMAN, BARRY J. Self-Efficacy: An essential motive to learn Contemporary. Educational Psychology 25, 82-91, (2000) Disponivel em: http://www.idealibrary.com Acesso em 25.08.2014

YIN, R. K. Estudo de caso: planejamento e métodos. 5. ed. Porto Alegre: Bookman, 2015. $320 \mathrm{p}$. 
SAMPIERI, R. H.; COLLADO, C. F.; LUCIO, M. P. B. Metodologia de pesquisa. 5. ed. Porto Alegre: AMGH, 2013. 624p. (Série Métodos de Pesquisa). 